\title{
KAJIAN TERHADAP AKSESIBILITAS FISIK BAGI TUNANETRA DAN TUNADAKSA DI GEDUNG LPPMP UNY
}

\author{
Sativa1 dan Yasika Barra Bactiar ${ }^{2}$ \\ 1,2 Jurusan Pendidikan Teknik Sipil dan Perencanaan, FT, UNY \\ Email: sativa@uny.ac.id
}

\begin{abstract}
ABSTRAK
Kajian tentang aksesibilitas berkaitan erat dengan fungsi ruang, akses menuju ruang, elemen bangunan dan seting komponen. Paper ini akan menjelaskan bagaimana kemampuan fasilitas fisik di Kampus Universitas Negeri Yogyakarta dalam mengakomodasi kebutuhan penyandang disabilitas. Evaluasi ini difokuskan pada Gedung Lembaga Pengembangan dan Penjaminan Mutu Pendidikan (LPPMP) UNY. Kajian ini merupakan kajian deskriptif kuantitatif. Pengumpulan data dilakukan dengan observasi bangunan dan pengukuran pada elemen sarana aksesibilitas. Pengelompokan data dibuat berdasarkan elemen aksesibilitas yang setipe. Analisis data dilakukan dengan cara mengkomparasikan dengan standar perencanaan bangunan aksesibel yang telah ditetapkan oleh Kementrian Pekerjaan Umum dan Perumahan Rakyat (PUPR). Hasil dari kajian evaluasi didapatkan bahwa aksesibilitas tunanetra 70,86\%, dan aksesibilitas tunadaksa 75,115\%. Nilai 70,86\% menunjukkan aksesibilitas tunanetra masuk dalam kategori "tidak andal", sementara $75,115 \%$ menunjukkan aksesibilitas tunadaksa masuk dalam kategori "kurang andal". Hasil studi ini dapat menjadi referensi untuk pengembangan bangunan LPPMP maupun fasilitas fisik lain di lingkungan UNY yang lebih ramah difabel ke depan..
\end{abstract}

Kata Kunci: aksesibilitas, disabilitas, LPPMP UNY

\begin{abstract}
Study on accessibility is closely related to space functions, access to spaces, building elements, and component settings. The paper explained the ability of Universitas Negeri Yogyakarta (UNY) infrastructure to accommodate the needs of disabilities. This paper was focused on the LPPMP (Lembaga Pengembangan dan Penjaminan Mutu Pendidikan) Building UNY. This study used descriptive quantitative method. The data were collected by building observations, and measurements on accessibility elements. Grouping data was managed based on elements with typical forms. Data analysis was done by comparing with accessible building planning standards established by the Ministry of Public Works and Public Housing (PUPR). The results of the evaluation study found that accessibility for the blind and low vision people was $70.86 \%$ (indicates that accessibility is not reliable), and accessibility for orthopedically handicapped was $75.115 \%$ (indicates that the accessibility is less reliable). The result of this research is important to be a reference in development of LPPMP building and other infrastructure in $U N Y$ in the next, especially in order to be disability friendly campus building
\end{abstract}

Keyword: accessibility, disability, LPPMP UNY

\section{PENDAHULUAN}

Pendidikan adalah hak semua warganegara, termasuk bagi kaum difabel. Oleh karena itu, kebutuhan penyandang disabilitas untuk mendapatkan pendidikan yang layak harus turut serta difasilitasi oleh pemerintah. Universitas Negeri Yogyakarta (UNY) sebagai salah satu perguruan tinggi negeri Indonesia berkomitmen untuk mewujudkan kampus inklusif, salah satunya dengan memfasilitasi pembentukan unit layanan disabilitas.
Namun demikian secara fisi juga perlu dikaji lebih jauh bagaimana kesiapan kampus dalam melayani kaum difabel tersebut, salah satunya dengan melakukan studi ini.

Riset ini mengambil lokus Gedung Lembaga Pengembangan dan Penjaminan Mutu Pendidikan (LPPMP), sebagai pusat pengembangan penjaminan mutu pendidikan bagi mahasiswa UNY. Kajian ditinjau dari segi aksesibilitas terhadap 
penyandang difabel khususnya tunanetra dan tunadaksa (pengguna kruk dan kursi roda). Hasil temuan data di lapangan kemudian akan dilakukan analisis dan dikomparasikan dengan beberapa standar yang telah ditetapkan, yaitu: Peraturan Menteri Pekerjaan Umum PRT/M/No. 30 Th 2006, PRT/M/No. 14 Th 2017, dan Manual Desain Bangunan Aksesibel (SAPPK ITB).

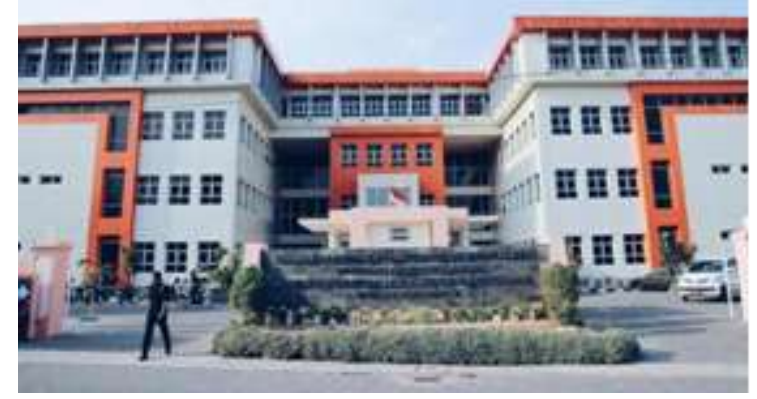

Gambar 1. Gedung LPPMP UNY

Aksesibilitas bagi penyandang disabilitas merupakan salah satu sarana untuk membuat kehidupan difabel menjadi lebih baik (Lubis, 2008). Sejalan dengan itu yang dimaksud dengan aksesibilitas fisik adalah fasilitas yang dapat dituju, dilewati, dimasuki, dan dapat dipergunakan oleh penyandang disabilitas, dengan kemandirian mereka masing-masing (Putri, 2011).

Kurangnya penghargaan dan apresiasi terhadap difabel dapat menyebabkan sedikitnya akses yang diterima oleh difabel dan berimbas pada hilangnya hak terhadap penggunaan fasilitas yang seharusnya mereka dapatkan.

\section{METODE}

Penelitian ini merupakan penelitian deskrptif kuantitatif, yang dilakukan dengan observasi dan pengukuran elemen aksesibilitas di lapangan. Pengukuran pada sarana aksesibilitas dibatasi pada fasilitas yang ada di luar dan fasilitas yang ada di dalam Gedung LPPMP. Total item yang dilakukan pengukuran adalah 11 item. Luas bangunan Gedung LPPMP 6800 m².

Pengumpulan data yang digunakan dalam studi ini menggunakan beberapa metode berikut:

a.Observasi

Metode observasi merupakan peninjauan langsung ke lapangan, dengan melakukan peninjauan terhadap item di dalam dan di luar bangunan gedung yang akan dikaji. Selain itu juga untuk memverifikasi keakuratan data sekunder yang berupa arsip gambar kerja bangunan (as built drawing) LPPMP UNY.

b.Pengukuran

Setelah dilakukan pembacaan pada arsip gambar kerja bangunan kemudian dilakukan pengecekan dimensi terhadap fasilitas yang menjadi kajian evaluasi. Setiap item aksesibilitas yang ada dicermati secara mendetail baik dari segi bentuk, ukuran dasar ruang, penempatan, sirkulasi dan tata ruang bangunan.

c.Dokumentasi

Pengumpulan data melalui dokumentasi diperoleh melalui peninjauan langsung ke lapangan dan memotret sarana aksesibilitas di Gedung LPPMP UNY.

Selanjutnya analisis data dilakukan dengan mengkomparasikan data dengan standar perencanaan bangunan aksesibel. Terdapat tiga standar yang digunakan sebagai acuan yaitu Persyaratan Teknis Fasilitas dan Aksesibilitas (Peraturan Menteri Pekerjaan Umum No. 30/PRT/M/ Tahun 2006), Manual Desain Bangunan Aksesibel (SAPPK ITB) dan Persyaratan Teknis Fasilitas dan Aksesibilitas (Peraturan Menteri Pekerjaan Umum No. 14/PRT/M/Tahun 2017).

Kategori penilaian akhir didapatkan dari Tabel Kriteria Nilai Keandalan Bangunan Gedung. Penilaian ini menggunakan standar Kementerian PUPR dari Direktorat Jenderal Perumahan dan Pemukiman (Tabel 1). Ada 5 aspek yang menjadi 
tinjauan, terdiri dari arsitektural elemen, aksesibilitas, struktur, utilitas proteksi kebakaran, serta bangunan dan lingkungan. Dalam kajian evaluasi ini yang digunakan adalah aspek keandalan bangunan berdasarkan tingkat aksesibilitas dari pengguna gedung.

Tabel 1. Kriteria Nilai Keandalan Bangunan Gedung

\begin{tabular}{|c|c|c|c|c|c|c|c|c|c|}
\hline \multirow[b]{2}{*}{ No } & \multirow[b]{2}{*}{$\begin{array}{l}\text { Aspek yang } \\
\text { Dinilai }\end{array}$} & \multicolumn{8}{|c|}{ Kriteria Penilaian (\%) } \\
\hline & & Andal & Nilai K & $\begin{array}{c}\text { Kurang } \\
\text { Andal }\end{array}$ & Nilai K & $\begin{array}{l}\text { Tidak } \\
\text { Andal }\end{array}$ & Nilai K & $\begin{array}{c}\text { Bobot } \\
(\%)\end{array}$ & $\begin{array}{c}\text { Total Andal } \\
(\%)\end{array}$ \\
\hline 1 & Arsitektur & $95-100$ & & $75<95$ & & $<75$ & & 10.00 & \\
\hline 2 & Struktur & $95-100$ & & $75<95$ & & $<75$ & & 30.00 & \\
\hline 3 & $\begin{array}{l}\text { Utilitas } \\
\text { Proteksi } \\
\text { Kebakaran }\end{array}$ & $95-100$ & & $75<95$ & & $<75$ & & 50.00 & \\
\hline 4 & Aksesbilitas & $95-100$ & & $75<95$ & & $<75$ & & 5.00 & \\
\hline 5 & $\begin{array}{l}\text { Tata Bangunan } \\
\text { dan Lingkungan }\end{array}$ & $95-100$ & & $75<95$ & & $<75$ & & 5.00 & \\
\hline & & & Jumlah & & & & & 100.00 & \\
\hline & angunan yang dipe & ksa: - & & & & & Masuk & egori: - & \\
\hline
\end{tabular}

Keterangan: Andal : $\mu \mathrm{ku}=95-<100 \%$; Kurang andal $: \mu \mathrm{ku}=75-<95 \%$; Tidak andal $: \mu \mathrm{ku}=<75 \%$

Sumber: Kementerian PUPR Direktorat Jenderal Perumahan dan Pemukiman, 2018

Skala penilaian yang digunakan adalah scoring, pada setiap elemen aksesibilitas dibedakan menjadi 3 tingkatan dengan skor penilain tertinggi adalah 3 poin, dengan kriteria "andal", 2 poin untuk kriteria "kurang andal", dan penilaian terendah mendapatkan 1 poin dengan kriteria "tidak andal". Parameter yang digunakan mengacu pada Tabel 1. Kriteria pembagian skor penilaian sesuai dengan kondisi fasilitas yang ada di lapangan:

Tabel 2. Penilaian Elemen Aksesbilitas

\begin{tabular}{ccccc}
\hline No & Klasififikasi & Skor & $\begin{array}{c}\text { Rentan } \\
\text { Nilai }\end{array}$ & $\%$ \\
\hline 1 & Andal & 3 & $95-100$ & $66,67-100$ \\
\hline
\end{tabular}

\begin{tabular}{clccc}
\hline No & Klasififikasi & Skor & $\begin{array}{c}\text { Rentan } \\
\text { Nilai }\end{array}$ & $\%$ \\
\hline 2 & Kurang Andal & 2 & $75<95$ & $33,4-66,66$ \\
3 & Tidak Andal & 1 & $<75$ & $0-33,33$ \\
\hline
\end{tabular}

Skala penilaian yang diberikan pada masing-masing kategori setiap elemen tergantung pada kesesuaiannya dengan standar. Nilai persentase yang didapatkan setelah melakukan komparasi dengan standar kemudian dimasukkan kedalam tabel kategori keandalan bangunan, sehingga akan didapatkan kriteria aksesibilitas masing-masing difabel pada Gedung LPPMP.

\section{HASIL DAN PEMBAHASAN}

Hasil dan pembahasan dijelaskan dalam tiga tahap yakni analisis penilaian elemen, penilaian aksesibiltas difabel dan rekapitulasi penilaian aksesibilitas.

Analisis penilaian elemen aksesibilitas di Gedung LPPMP menggunakan metode komparasi dengan Peraturan Perundangundangan yang telah ditetapkan oleh Pemerintah. Ada 2 klasifikasikan kelompok difabel yaitu tunanetra dan tunadaksa (dalam hal ini adalah pengguna kruk dan pengguna kusi roda). Berikut ini adalah 11 elemen yang menjadi pembahasan pada kajian ini.

\begin{tabular}{cl} 
Tabel & Daftar Elemen Aksesbilitas \\
\hline No & Elemen/Sarana Fasilitas \\
\hline 1 & $\begin{array}{l}\text { Jalur akses utama menuju } \\
\text { bangunan gedung }\end{array}$ \\
2 & $\begin{array}{l}\text { Sitem peralatan dan perlengkapan } \\
\text { kontrol }\end{array}$ \\
3 & Tempat parkir \\
\hline
\end{tabular}




\begin{tabular}{cl}
\hline No & \multicolumn{1}{c}{ Elemen/Sarana Fasilitas } \\
\hline 4 & Ramp \\
5 & Tangga darurat \\
6 & Toilet \\
7 & Rute utama pejalan kaki (jalur \\
& pedestrian) \\
8 & Jalur pemandu, guiding block di \\
& dalam gedung \\
9 & Pintu \\
10 & Lift \\
11 & Mushola \\
\hline \multicolumn{2}{c}{ Sumber: Permen $P U, 2006-2007$}
\end{tabular}

Penilaian pada kajian evaluasi ini berdasarkan pada kesesuaian elemen dengan kategori dari masing masingdifabel, dan omparasi dengan standar yang dijadikan rujukan. Nilai yang didapatkan disajikan dalam bentuk presentase. Penilaian elemen dirumuskan:

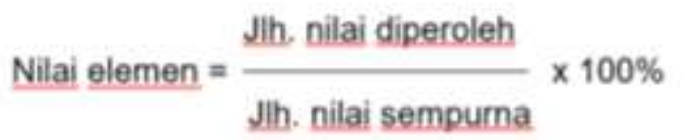

Penilaian aksesibilitas penilaian difabel, penilaian ini ditinjau dari masing-masing difabel yang menjadi aspek kajian dalam evaluasi yaitu tunanetra dan tunadaksa. Pada dasarnya bangunan gedung LPPMP ini belum dilakukan pengaplikasian tentang standar fasilitas sarana yang aksesibel bagi penyandang disabilitas. Masih banyak sekali sarana di dalam gedung yang belum sesuai standar. Akan tetapi potensi dari akses dan sirkulasi antar ruang yang masih sangat terbuka, sehingga sangat memungkinkan untuk dilakukan penambahan elemen aksesibilitas pada banguan gedung. Untuk tunanetra sendiri perlu ditambahkan ubin pemandu/guiding block pada lantai di dalam bangunan minimal menuju pada fasilitas umum yang ada di dalam bangunan seperti mushola, toilet umum, lift, tangga darurat, dan lainlain.

Penambahan petunjuk yang bertuliskan huruf braille pada setiap papan ramburambu akan banyak membantu penyandang tunanetra dalam memahami setiap petunjuk yang ada di Gedng LPPMP. Selain itu penambahan cahaya pada tangga darurat pada setiap nosing tangga juga dibutuhkan oleh tunanetra yang mengalami kebutaan sebagian. Selaian renovasi di dalam gedung perbaikan di luar gedung juga dibutuhkan seperti perbaikan pada jalur pedestrian, dan tempat parkir kendaraan yang belum menyediaakan tempat parkir khusus bagi penyandang difabel.

Tabel 4. Penilaian Aksesbilitas Tunanetra pada Gedung LPPMP UNY

\begin{tabular}{|c|c|c|c|c|c|}
\hline \multirow{2}{*}{ No } & \multirow{2}{*}{ Elemen Aksesbilitas } & \multicolumn{2}{|c|}{ Kriteria Penilaian (\%) } & \multirow{2}{*}{$\begin{array}{c}\text { Dalam } \\
(\%)\end{array}$} & \multirow{2}{*}{ Ket. } \\
\hline & & A $\quad$ B & C & & \\
\hline 1 & Jalur pemandu & & $\mathrm{V}$ & 59,52 & Tidak andal \\
\hline 2 & Ramp & & V & 42,22 & Tidak andal \\
\hline 3 & Sistem peralatan dan perlengkapan kontrol & & $\mathrm{V}$ & 75,00 & Tidak andal \\
\hline 4 & Lift & V & & 100 & Andal \\
\hline 5 & Mushola & & $\mathrm{V}$ & 72,22 & Tidak andal \\
\hline 6 & Pintu & V & & 89,94 & Kurang andal \\
\hline 7 & Parkir & & V & 54,16 & Tidak andal \\
\hline 8 & Tangga darurat & $\mathrm{V}$ & & 86,67 & Kurang andal \\
\hline 9 & Toilet umum & & V & 70,89 & Tidak andal \\
\hline 10 & Pedestrian pejalan kaki & & V & 73,33 & Tidak andal \\
\hline 11 & Akses utama gedung & & V & 55,55 & Tidak andal \\
\hline & Jumlah & & & 779,50 & \\
\hline & Rata-rata & & & 70,86 & Tidak andal \\
\hline
\end{tabular}

Dari tabel 4 diketahui bahwa untuk rekapitulasi akhir persentase nilai aksesibilitas tunanetra pada bangunan Gedung LPPMP adalah $=70,86 \%$, masuk dalam kategori "Tidak andal".
Sirkulasi antar ruang pada Gedung LPPMP yang masih sangat terbuka membuat penyandang tunadaksa pengguna alat bantu kruk tidak terlalu kesulitan dalam mengakses ruangan yang ada di dalam gedung. Permasalahan bagi 
pengguna alat bantu kurk justru terdapat pada fasilitas penunjang gedung, seperti pada toilet umum. Toilet yang ada di Gedung LPPMP memang pada dasarnya tidak diprioritaskan untuk penyandang difabel, sehingga ukuran ruangan pada setiap kamar toilet juga tidak disesuaikan dengan kebutuhan penyandang disabilitas. Pintu pada toilet juga memiliki lebar yang tidak sesuai dengan standar sehingga kurang aksesibel bagi difabel (kruk).
Pada tempat parkir juga belum desidiakan tempat parkir khusus untuk penyandang disabilitas. Padahal dalam peraturan sudah dijelaskan bahwa penyediaan lahan parkir untuk difabel minimal seluas $2 \%$ dari seluruh luas bangunan. Selaian itu keberadaan fasilitas pembantu seperti penyediaan tempat duduk (kursi) pada tempat wudhu juga akan sangat membatu penyandang disabilitas dalam melakukannya secara mandiri.

Tabel 5. Penilaian Aksesbilitas Tunadaksa pengguna Kruk

\begin{tabular}{|c|c|c|c|c|c|c|}
\hline \multirow{2}{*}{ No } & \multirow{2}{*}{ Elemen Aksesbilitas } & \multicolumn{3}{|c|}{ Kriteria Penilaian (\%) } & \multirow{2}{*}{$\begin{array}{c}\text { Dalam } \\
(\%)\end{array}$} & \multirow{2}{*}{ Ket. } \\
\hline & & A & B & C & & \\
\hline 1 & Jalur pemandu & & $\mathrm{V}$ & & 76,15 & Kurang andal \\
\hline 2 & Ramp & & $\mathrm{V}$ & & 75,55 & Kurang andal \\
\hline 3 & Sistem peralatan dan perlengkapan kontrol & V & & & 100 & Andal \\
\hline 4 & Lift & & V & & 80,95 & Kurang andal \\
\hline 5 & Mushola & & V & & 88,89 & Kurang andal \\
\hline 6 & Pintu & & $\mathrm{V}$ & & 84,91 & Kurang andal \\
\hline 7 & Parkir & & V & & 79,16 & Kurang andal \\
\hline 8 & Tangga darurat & & & $\mathrm{V}$ & 40 & Tidak andal \\
\hline 9 & Toilet umum & & & V & 54,49 & Tidak andal \\
\hline 10 & Pedestrian pejalan kaki & & V & & 86,66 & Kurang andal \\
\hline \multirow[t]{3}{*}{11} & Akses utama gedung & & V & & 77,77 & Kurang andal \\
\hline & Jumlah & & & & 844,53 & \\
\hline & Rata-rata & & & & 76,77 & Kurang andal \\
\hline
\end{tabular}

Dari tabel 5 diketahui bahwa rekapitulasi akhir persentase nilai aksesibilitas tunadaksa pengguna alat bantu kruk pada bangunan Gedung LPPMP adalah = $76,77 \%$, masuk dalam kategori "Kurang andal".

Tunadaksa (Kursi roda), sirkulasi antar ruang pada Gedung LPPMP yang masih sangat terbuka membuat penyandang tunadaksa pengguna alat bantu kursi roda tidak terlalu kesulitan dalam mengakses ruangan yang ada di dalam gedung. Kebutuhan dasar (ukuran ruang minimal) dari luas yang dibutuhkan oleh difabel pengguna alat bantu kruk dan pengguna kursi roda sama. Sehingga jika pengguna kruk dapat mengakses tempat tertentu pengguna kursi roda juga akan bisa mengaksesnya.

Penyediaan elemen pendukung pada bangunan memang sangat dibutuhkan. Terlebih bagi para penyandang disabilitas yang hendak mengakses ruangan di dalam gedung tersebut. Harapannya elemen penunjang tersebut dapat mengurangi usaha mereka dalam menjangkau seluruh tempat di dalam bangunan dengan mandiri.

Tabel 6. Penilaian Aksesbilitas Tunadaksa pengguna Kursi Roda

\begin{tabular}{|c|c|c|c|c|c|c|}
\hline \multirow{2}{*}{ No } & \multirow{2}{*}{ Elemen Aksesbilitas } & \multicolumn{3}{|c|}{ Kriteria Penilaian (\%) } & \multirow{2}{*}{$\begin{array}{c}\text { Dalam } \\
\text { (\%) }\end{array}$} & \multirow{2}{*}{ Ket. } \\
\hline & & A & B & C & & \\
\hline 1 & Jalur pemandu & & & V & 61,58 & Tidak andal \\
\hline 2 & Ramp & & & V & 71,10 & Tidak andal \\
\hline 3 & Sistem peralatan dan perlengkapan kontrol & V & & & 100 & Andal \\
\hline 4 & Lift & & V & & 80,95 & Kurang andal \\
\hline 5 & Mushola & & V & & 88,89 & Kurang andal \\
\hline 6 & Pintu & & $\mathrm{V}$ & & 79,89 & Kurang andal \\
\hline 7 & Parkir & & & $\mathrm{V}$ & 75 & Tidak andal \\
\hline
\end{tabular}




\begin{tabular}{|c|c|c|c|c|c|}
\hline \multirow{2}{*}{ No } & \multirow{2}{*}{ Elemen Aksesbilitas } & \multicolumn{2}{|c|}{ Kriteria Penilaian (\%) } & \multirow{2}{*}{$\begin{array}{c}\text { Dalam } \\
(\%)\end{array}$} & \multirow{2}{*}{ Ket. } \\
\hline & & A $\quad$ B & C & & \\
\hline 8 & Tangga darurat & & $\mathrm{V}$ & 40 & Tidak andal \\
\hline 9 & Toilet umum & & $\mathrm{V}$ & 51,85 & Tidak andal \\
\hline 10 & Pedestrian pejalan kaki & V & & 86,66 & Kurang andal \\
\hline 11 & Akses utama gedung & & V & 72,22 & Tidak andal \\
\hline & $\begin{array}{l}\text { Jumlah } \\
\text { Rata-rata }\end{array}$ & & & $\begin{array}{c}808,14 \\
73,46\end{array}$ & Tidak andal \\
\hline
\end{tabular}

Dari tabel 6 bisa dilihat bahwa rekapitulasi akhir persentase nilai aksesibilitas tunadaksa pengguna alat bantu kursi roda pada bangunan Gedung LPPMP adalah = $73,46 \%$, masuk dalam kategori "Tidak andal". Setelah dilakukan penilaian pada setiap elemen terhadap masing-masing kategori difabel, nilai aksesibilitas tunadaksa pengguna (kruk), dan nilai aksesibilitas tunadaksa (kursi roda) kemudian dijumlahkan untuk mendapatkan nilai rata-rata aksesibilitas difabel tunadaksa terhadap gedung LPPMP.

Tabel 7. Aksesibilitas tunadaksa

\begin{tabular}{rcc}
\hline No & Kategori difabel & Persentase Nilai \\
\hline 1 & Tunadaksa (kruk) & $76,77 \%$ \\
2 & Tunadaksa (kursi roda) & $73,46 \%$ \\
& Jumlah & $150,23 \%$ \\
& Rata-rata & 75,115 \\
\hline
\end{tabular}

Nilai aksesibilitas tunadaksa pada Gedung LPPMP adalah $75,115 \%$, Persentase nilai tersebut masuk dalam kategori "Kurang andal". Rekapituasi ini merupakan penilaian akhir yang digunakan sebagai penarikan kesimpulan, berapa persen nilai aksesibilitas masing-masing difabel pada Gedung LPPMP.

\section{DAFTAR RUJUKAN}

Budi M H, dkk. (2014). Evaluasi Kinerja Simpang Tidak Bersinyal Jalan Raya Mengkreng Kabupaten Jombang. Jurnal Rekayasa Sipil ISSNN 19785658. 8(3): 174-180.

Direktorat Pembinaan Jalan Kota. (1997). Manual Kapasitas Jalan Indonesia (MKJI) 1997. Jakarta: Direktorat
Tabel 8. Rekapitulasi aksesibilitas difabel

\begin{tabular}{ccc}
\hline No & Kategori difabel & Persentase Nilai \\
\hline 1 & Tunanetra & $70,86 \%$ \\
2 & Tunadaksa & $75,115 \%$ \\
& Jumlah & $147,63 \%$ \\
& Rata-rata & $73,81 \%$ \\
\hline
\end{tabular}

\section{SIMPULAN}

Dari kajian evaluasi aksesibilitas difabel terhadap elemen aksesibilitas Gedung LPPMP sebagai salah satu fasilitas publik (bidang pendidikan) didapatkan bahwa aksesibilitas untuk tunanetra pada Gedung LPPMP adalah $70,86 \%$ yang menunjukkan kategori "Tidak andal". SEmentara itu aksesibilitas untuk tunadaksa pada Gedung LPPMP adalah 75,115\%. Nilai ini termasuk dalam kategori "Kurang andal".

Hasil studi ini diharapkan dapat menjadi salah satu referensi bagi pengembangan fisik gedung LPPMP UNY maupun bangunan lain di lingkungan kampus UNY, agar lebih ramah terhadap difabel. Paling tidak, setiap lantai dasar bangunan dapat diupayakan untuk memenuhi kebutuhan aksibilitas bagi kaum disabilitas, sesuai dengan standar yang telah dtetapkan pemerintah.

Jenderal Bina Marga, Kementerian Pekerjaan Umum.

Febrian F. (2014). Analisis Perencanaan Penerapan Persimpangan Bersinyal Dinamis (Actuated Traffic Control System) pada Persimpangan di Kota Palembang. Jurnal Teknik Sipil dan Lingkungan. 2(3): 397-406.

Galfi M. (2012). Studi Simpang Bersinyal pada Simpang 4 (Empat) Sempaja 
Samarinda. Jurnal Keilmuan dan Aplikasi Teknik Sipil 1(1): 8-29.

Kementerian Perhubungan. (2015).

Pedoman Pelaksanaan Kegiatan

Manajemen dan Rekayasa Lalu

Lintas. Peraturan Menteri

Perhubungan Nomor PM 96 Tahun 2015. Jakarta (ID): Kemenhub.

Khisty J, Kent L. (2005). Dasar-dasar

Rekayasa Transportasi. Jakarta:

Erlangga.

Lumintang GYB, dkk. (2013). Kinerja Lalu Lintas Persimpangan Lengan Empat Bersignal (Studi Kasus: Persimpangan Jalan Walanda Maramis Manado). Jurnal Sipil Statik 1(3): 202-208.

Pratama, G. N. I. P., \& Sumarjo, H. (2018). Aksesibilitas Tata Letak Elevator Penumpang Gedung Kantor Pusat Layanan Terpadu (KPLT) Fakultas
Teknik UNY. INformasi dan Ekspose hasil Riset Teknik Slpil dan Arsitektur, 14(1), 26-35.

Puspita W A. (2010). Analisis Manajemen Lalu Lintas terhadap Persimpangan Jalan Raya Kletek-Jalan Sawunggaling Akibat Adanya Pusat Perdagangan Agrobisnis (PUSPA AGRO) Jawa Timur. Surabaya (ID): Institut Teknologi Sepuluh November.

Rahayu G, dkk. (2009). Analisis Arus Jenuh dan Panjang Antrian pada Simpang Bersinyal: Studi Kasus di Jalan Dr. SutomoSuryopranoto, Yogyakarta. Jurnal IImiah Semesta Teknika 12(1): 99-108.

William R. (2010). Analisis Panjang Antrian Simpang Bersinyal dengan Menggunakan Metode MKJI (Studi Kasus Simpang Jalan Affandi Yogyakarta). Yogyakarta (ID): Universitas Atma Jaya Yogyakarta. 